\title{
AS DIRETRIZES CURRICULARES DOS CURSOS DE DIREITO À LUZ DAS IDEIAS DE SAN TIAGO DANTAS
}

\author{
José Sebastião de Oliveira \\ Doutor, professor, Programa de Pós-Graduação em Ciên- \\ cias Jurídicas/Mestrado, Centro Universitário Maringá (Uni- \\ cesumar) - Maringá (PR), Brasil. drjso@brturbo.com.br
}

\section{Andrea Souza Correa Lima}

Mestranda, Programa de Pós-Graduação em Ciências Jurídicas/Mestrado, Centro Universitário Maringá (Unicesumar)

- Maringá (PR), Brasil. andrea_pesquisa@yahoo.com.br

\section{Resumo:}

0 presente artigo tem por objetivo analisar os elementos que totalizam a estrutura curricular dos cursos de Direito no Brasil, relacionando-os à ótica da crítica de Francisco Clementino San Tiago Dantas. Para este fim, examina-se os preceitos da Portaria 1.886/94 e os termos da Resolução CNE/CES no 9/2004, do Conselho Nacional de Educação, para dimensionar as especificidades que ambas traçaram para as diretrizes curriculares nacionais para 0 curso de Direito. Como objetivos, procura-se verificar em que pontos a instrução normativa do Ministério da Educação atendeu às expectativas de sua edição, conferindo, ou não, uma nuance humanista ao ensino jurídico. Para tanto adota-se método de abordagem dedutivo e utiliza-se a pesquisa bibliográfica e documental.

\section{Palavras-chave:}

Educação. Diretrizes curriculares. Formação jurídica. San Tiago Dantas.

\section{THE CURRICULAR GUIDELINES OF THE COURSES OF LAW IN THE LIGHT OF THE IDEAS OF SAN TIAGO DANTAS}

\section{Abstract:}

The article aims to analyze the elements that total the curricular structure of the Law Courses in Brazil, relating them to the optics of the critic of Francisco Clementino San Tiago Dantas. Therefore, the precepts of Administrative Rule 1,886 / 94 and the terms of Resolution CNE/ CES No. 9/2004, of the National Education Council, are examined in order to assess the specificities that both have drawn for the national curricular guidelines for the Course of Right. As objectives, it is sought to verify in which points the normative instruction of the Ministry of Education met the expectations of its edition, conferring, or not, a humanistic nuance to the legal education. For that, a method of deductive approach is adopted, and bibliographic and documentary research is used.

\section{Keywords:}

Education. Curricular guidelines. Legal training. San Tiago Dantas. 


\section{Sumário:}

1 Introdução. 2 A Gênese das Diretrizes Curriculares do Curso de Direito Previstas na Resolução CNE/CES no 9/2004: a influência do pensamento de San Tiago Dantas. 3 A Finalidade da Resolução CNE/CES n $\square$ 9/2004 e a Retomada da Base Humanística Sugerida por San Tiago Dantas. 4 Considerações Finais. 5 Referências.

Recebido em: 24/10/2017

Aceito em: 6/12/2017 


\section{INTRODUÇÃO}

Passada mais de uma década da edição da Resolução CNE/CES n n 9/2004, que reestruturou as Diretrizes Curriculares Nacionais do curso de Direito, o ensino jurídico no Brasil prossegue distante de uma adequação às normas da Lei de Diretrizes e Bases da Educação, como também se afasta das exigências e demandas de uma sociedade que enfrenta constantes e traumáticas transformaçôes, como a brasileira.

A situação do ensino jurídico brasileiro é tão preocupante que, desde 2015, o Conselho Nacional de Educação retomou o debate acerca da necessidade de reformulação das Diretrizes Curriculares dos cursos de Direito. Dentro deste espaço de diálogo com a sociedade, a Ordem dos Advogados do Brasil, por meio de seus representantes, tem indicado alguns aspectos relevantes para a discussão, como a interdisciplinaridade, a internacionalização e os eixos formacionais.

Nesse sentido, a Comissão de Educação Jurídica do Conselho Federal da Ordem dos Advogados do Brasil (OAB) realizou duas audiências públicas com a participação de representantes de Instituiçôes de Ensino Superior das distintas unidades federativas brasileiras. A primeira audiência foi efetivada em 11 de abril de 2017, na sede do Conselho Federal da OAB, em Brasília, e teve como pauta principal, além dos temas já suscitados junto ao Conselho Nacional de Educação, a análise das demandas da contemporaneidade, apreciando aspectos relacionados ao empreendedorismo, às novas metodologias pedagógicas e à interação com a sociedade (BRASIL, 2017). No dia 6 de junho, novamente na sede do Conselho Federal da Ordem dos Advogados do Brasil, a entidade promoveu a segunda audiência pública, quando priorizou o debate sobre a qualidade do ensino jurídico, tendo em vista que "[...] os indicadores dos egressos dos cursos de Direito no Brasil não são bons e demonstram que a qualidade do ensino está fragilizada" (ORDEM..., 2017).

De uma ou de outra forma, a OAB provoca o questionamento sobre a necessidade de incorporar à formação jurídica subsídios que ofereçam uma melhor condição de autonomia e independência intelectual do acadêmico, assim como elementos didático-pedagógicos que lhe permitam estabelecer um relacionamento direto com as questôes sociais, a exemplo da temática indígena, étnico-racial, de 
gênero e tecnológicas, proporcionando ao acadêmico de Direito um contato mais sólido e efetivo com os fenômenos vivenciados pela sociedade (UNIVERSIDADE..., 2017).

Diante deste quadro, e considerando-se que o ensino jurídico vivencia uma conjuntura de atipicidade que já era identificada em meados da década de 50 pelo célebre professor Francisco Clementino San Tiago Dantas, que, em discurso proferido na aula inaugural do curso de Direito da Faculdade Nacional da Universidade do Brasil elevou ao caos a situação da formação em Direito, seccionando-o do controle e atuação social, urge analisar-se o padrão preceitual que orienta a criação dos cursos de Direito e o concernente processo de ensino e aprendizagem, como forma de ajustamento do perfil profissional do egresso dessa habilitação.

Para isto, realiza-se o exame da pauta normativa estabelecida pela Portaria 1.886/1994 e pela Resolução CNE/CES no 9/2004, instituidoras das diretrizes nacionais curriculares do curso de Direito, dentro de seu respectivo espaço e tempo de edição e vigência. $\mathrm{O}$ objetivo é equalizar a acepção normativa das referidas expressôes ministeriais com o enunciado axioprincipiológico presente na crítica de San Tiago Dantas, de maneira que se consiga identificar a essência dispositiva de viés humanista no âmago da formação jurídica. Para tanto utilizou-se do método dedutivo e da pesquisa bibliográfica e documental, no intuito de compreender a gênese das diretrizes curriculares vigentes, bem como verificar a finalidade a que se destinou a Resoluçáo no 9/2004 neste processo contínuo de reformulaçáo da educação jurídica no Brasil.

\section{A GÊNESE DAS DIRETRIZES CURRICULARES DO CURSO DE DIREITO PREVISTAS NA RESOLUÇÃO CNE/CES No 9/2004: A Influência do Pensamento de San Tiago Dantas}

A Resolução CNE/CES no 9/2004, que fixa as atuais diretrizes curriculares do curso de Direito no Brasil, surge com o intuito de aprimorar as iniciativas propostas pela Portaria no 1.886/1994, além de buscar consonância com a Lei de Diretrizes e Bases da Educação Nacional (LDB), Lei no 9.394, de 20 de dezembro de 1996. 
Nesse sentido, o Conselho Nacional de Educação (CNE), vinculado ao Ministério da Educação e Cultura, atento às críticas da época, emitiu o parecer CNE no 776/97, assinalando a necessidade de uma readequaçáo das diretrizes curriculares previstas na Portaria $\mathrm{n}^{\circ} 1.886$ à nova realidade intrínseca aos princípios orientadores da educaçáo brasileira, preconizados pela LDB.

Sob esta ótica, o CNE observou que alguns pontos cruciais deveriam ser revistos, tais como: a excessiva rigidez decorrente do detalhamento de mínimos curriculares e a consequente redução da liberdade das instituiçóes de ensino em organizarem suas atividades; a prevalência de interesses corporativos que invocavam a adoção excessiva de disciplinas obrigatórias direcionadas diretamente ao mercado; a necessidade de estabelecer novas formas de aprendizagem no intuito de combater a evasão, bem como estimular programas de iniciação científica, próprios para o desenvolvimento da criatividade do discente, e, sobretudo, de uma postura de pertencimento em relação ao seu entorno. Para tanto, o CNE foi enfático ao manifestar a imperiosidade de incluir no Projeto Pedagógico do curso de Direito dimensóes éticas e humanistas, que suscitassem no estudante valores significativos que o levassem ao encontro com a efetividade do exercício da cidadania, tornando-se, pois, um profissional dotado de conteúdos técnicos, mas provido de um referencial humanístico (BRASIL, 1997). Este aspecto, por certo, revela o resgate dos debates que inflamaram as décadas de 40 e 50 , propagando uma forte crítica ao ensino jurídico no Brasil.

Dentro dessa realidade, observa-se como marco deste cenário de discussões o o discurso do professor Francisco Clementino de San Tiago Dantas, proferido na aula inaugural, em comemoração ao cinquentenário da Faculdade Nacional de Direito da Universidade do Brasil, em 25 de outubro de 1941. Naquela oportunidade o reconhecido docente, ao representar a congregação, expóe sua ansiedade diante de uma indiscutível crise no ensino jurídico brasileiro. Revela, então, o professor San Tiago Dantas, a sua convicção de que a formação jurídica se distanciava das grandes altercaçôes sociais, o que deveria provocar um redirecionamento das nuances da formação jurídica, de maneira que as faculdades de Direito encontrassem os meios adequados para contornarem o descompasso que existia entre o sistema educacional e a realidade socioeconômica brasileira. Isto, para o inolvidável docente, representaria uma verdadeira renovaçáo do ensino jurídico nacional (DURAN, 2006). 
No pináculo de sua insurgência contra o sistema formacional, San Tiago Dantas aduz que consideraria em crise, "no mundo de hoje, uma Faculdade em que o saber jurídico houvesse assumido a forma de um precipitado insolúvel, resistente a todas as reaçôes. Seria ela um museu de princípios e praxes, mas não seria um centro de estudos" (DANTAS, 2001, p. 17).

Sem embargo, foi a partir de outro célebre discurso de San Tiago Dantas, em 1955, que se colocou em evidência o contínuo desgaste do ensino jurídico, quando parte da análise do papel da universidade brasileira no processo educacional, associando-a ao modelo de outras universidades no mundo, tendentes à mecanização do ensino, mediante a singular transmissão de conhecimentos, para um "corpo estanque, desligando-se das bases existenciais que animam e vivificam esses conhecimentos, e que os unem ao destino histórico da própria sociedade" (DANTAS, 2009, p. 14). Nesse sentido, expressa a importância de se proceder a uma reanálise da universidade, com vistas ao resgate da função das Instituições de Ensino Superior como agentes transformadores, capazes de proporcionar instrumentos de cultura renováveis temporalmente, em cada época de restauração dos distintos fenômenos sociais. Seria esta, para Dantas, a forma pela qual a universidade e o ensino jurídico se amoldariam ao modelo adequado à satisfação das demandas da sociedade.

Sob este aspecto, Oliveira (2003) destaca três modelos de curso jurídico: o modelo cultural ou humanístico, cujas origens remontam à Idade Média, de forte cunho cultural e construtivista, preocupado em ensinar o jurista a pensar e criar o Direito, não buscava a solução de casos ou problemas jurídicos; o modelo profissionalizante ou técnico-informativo, de origem anglo-saxônica, colocou-se em oposição ao modelo cultural e teve sua aplicação nas colônias inglesas, em especial nos Estados Unidos, dotado de natureza puramente informativa, visava à formação do jurista como mero operador do Direito, focado exclusivamente na atividade forense, e o modelo misto-normativo ou de formação integral, desde uma concepção moderna, corresponde à cisão dos modelos cultural e técnico, visando à formação integral do jurista, adota, no processo formacional, um enfoque humanístico no início do curso e profissionalizante ao seu final (OLIVEIRA, 2003, p. 6-7).

Assim, o processo educacional universitário, que durante muito tempo teve como funções a propagação da alta cultura, a modelação do caráter e a estruturação do direcionamento social, passou a conjugar a dicotomia educação-trabalho, 
promovendo, portanto, uma cisão entre cultura geral e formação profissional, de forma a compatibilizar a formação profissional com uma educação humanística (SANTOS, 1989).

Nessa seara, a História revela uma preocupação exacerbada com a profissionalização dos processos formativos, acarretando num excesso de tecnicismo que ofuscou a ampla responsabilidade da educaçáo superior como instrumento de formação humana. Nesse sentido, "[...] a educação tem o condão de favorecer a adaptaçáo do homem ao seu ambiente de vida, adequando ao convívio com os demais. Neste processo pode-se contemplar o sentido da socialidade humana, e o caráter social da própria educação" (MIRANDA, 2017, p. 44).

Assim sendo, e diante da compreensão de que o Direito contribui com a classe dirigente, dimensionando os parâmetros de funcionamento da sociedade, tem-se que o modelo tradicional promove um verdadeiro paradoxo formativo, que impóe ao Direito o distanciamento do controle social e maximiza a eficiência de outras áreas do conhecimento no protagonismo de formação para a cidadania, como se observa nos cursos de Administraçáo e Economia.

Diante deste panorama, Dantas propóe uma urgente reformulação do ensino jurídico no Brasil, sugerindo necessidade de abandono do apego excessivo à técnica estanque e ao método tradicional de ensino, a exemplo da preleçóes expositivas coimbrãs, e buscar adotar-se uma metodologia que fosse além do estudo sistemático dos institutos e normas, e sobretudo, se voltasse para "[...] o preparo, o desenvolvimento, o treinamento e, afinal, o cabal desenvolvimento do raciocínio jurídico", de forma a possibilitar ao futuro profissional uma maior interação com a sociedade (DANTAS, 2009, p. 17). Dessa forma, Dantas sobreleva a necessidade de uma releitura da educação jurídica, devendo-se levar em conta o estabelecimento de um currículo flexível, com o ensino alicerçado sobre o desenvolvimento de habilidades, para o que sugere o método do estudo de caso e uma prática pedagógica efetiva.

Neste diapasão, menciona que o profissional em Direito, ao deixar os bancos acadêmicos, além de estar plenamente capacitado para o amplo exercício de sua atividade profissional, deve, mormente, haver-se aprofundado em determinadas áreas do Direito, por meio de um currículo flexível que “[...] permitisse, sem prejuízo da formação integral e da capacitação plena do futuro graduado, a sua aplicação maior 
a estudos de um ramo do Direito, que oferece no meio social possibilidades definidas de especialização" (DANTAS, 2009, p. 21). Adverte, ainda, que o verdadeiro ensino jurídico deve voltar-se para a formação de juristas preocupados com a vida em sociedade, com a construção de um raciocínio jurídico que os torne capazes de encontrar soluçóes que atendam às demandas da comunidade em que vivem.

A verdadeira educação jurídica, aquela que formará juristas para as tarefas da vida social, deve repetir esse esquema fundamental, colocando o estudante não em face de um corpo de normas, de que se levanta uma classificaçáo sistemática, como outra história natural, mas em face de controvérsias, de conflitos de interesses em busca de solução. Só desse modo a educação jurídica poderá conceituar com clareza o seu fim, que é formar o raciocínio jurídico e guiar o seu emprego na solução de controvérsias. O estudo das normas e instituições constitui um segundo objetivo, absorvido no primeiro, e revelado ao longo do exame e discussão dos problemas (DANTAS, 2009, p. 17).

Por último, Dantas ressalta a necessidade de se instituir uma prática de ensino mais efetiva, calcada no abandono do método tradicional expositivo e voltada para a liberdade do processo de ensino e aprendizagem, a partir da reflexáo sobre o Direito desde uma perspectiva sociojurídica, em que a norma deixa de ser o centro de análise e cede espaço aos fenômenos que ensejaram o surgimento da própria norma.

Aliás, ressalta-se que este pensamento refletiu nos ideais da educação jurídica nos anos 80 e 90, e encontra convergência com a própria Constituição Federal, que elencou, pelo disposto no artigo 206, os princípios vetores da educação formal no Brasil, em especial "a liberdade de aprender, ensinar, pesquisar e divulgar o pensamento, a arte e o saber; o pluralismo de idéias e de concepçóes pedagógicas e a garantia de padrão de qualidade" (BRASIL, 1998, p. 134).

Influenciada pela expressão dos princípios emanados da Carta Magna, a Lei no 9.394/1996, Lei de Diretrizes e Bases da Educação Nacional, exaltou a pertinência dos princípios da valorização da experiência extraescolar e da vinculação entre a educação escolar, o trabalho e as práticas sociais, entre outros (BRASIL, 1996).

Foi, no entanto, a edição da Portaria no $1.886 / 1994$, que estabeleceu um marco no ensino jurídico no Brasil, na década de 90, que tinha como pressuposto a influência de argumentos relevantes de outrora, tais como: 
1. o rompimento com o positivismo normativista;

2. a superação da concepção que só é profissional do Direito aquele que exerce atividade forense;

3. a negação da auto-suficiência ao Direito;

4. a superação da concepção de educação como sala de aula; e

5. a necessidade de um profissional com formação integral (interdisciplinar, teórica, crítica, dogmática e prática) (RODRIGUES, 2005, p. 97).

Em que pesem as intençóes de estabelecer diretrizes curriculares que promovessem reais melhorias na educação em Direito, momento em que estabeleceu um currículo mínimo para atender tal fim, a Portaria no 1.886/1994 sucumbiu diante da incapacidade dos partícipes do sistema educacional de promoverem uma autocrítica e dar passos rumo aos avanços que a Portaria propunha. Não bastasse, a Portaria no 1.886/1994 não correspondia às orientaçóes definidas pela Lei de Diretrizes e Bases, de 1996, e tampouco do Plano Nacional de Educação, Lei no 10.172, de 2001, que deliberou, dentre os objetivos e metas:

Estabelecer, em nível nacional, diretrizes curriculares que assegurem a necessária flexibilidade e diversidade nos programas oferecidos pelas diferentes instituiçôes de ensino superior, de forma a melhor atender às necessidades diferenciais de suas clientelas e às peculiaridades das regiôes nas quais se inserem [...] (BRASIL, 2001).

Por esta razão, a Portaria no $1.886 / 1994$, que sustentava a imperiosidade dos currículos mínimos, seguia na contramão da organização curricular de cunho axiológico, geral e humano, definida tanto pela Lei de Diretrizes e Bases da Educação quanto pelo Plano Anual de Educação, ambos adeptos ao estabelecimento de diretrizes comuns a todos os cursos, garantindo, porém, a "flexibilidade, a criatividade e a responsabilidade das instituiçôes ao elaborarem suas propostas curriculares" (BRASIL, 2002).

Assim, passados quase 50 anos do discurso pedagógico que San Tiago Dantas proferiu na aula inaugural da Faculdade Nacional de Direito, da Universidade do Brasil, o ensino jurídico brasileiro permaneceu sob os mesmos moldes educacio- 
nais de outrora, alicerçado na didática tradicional da aula monológica e tecnicista. Em oposição a este cenário, os princípios constitucionais e os preceitos da Lei de Diretrizes e Bases da Educação conformam a necessidade de resgatar-se o substrato diferenciado para o núcleo formativo em Direito, convergente com o pensamento do professor Francisco Clementino San Tiago Dantas.

Por este caminho, o Conselho Nacional de Educação, por meio do Parecer CES/CNE 0146/2002, procede a uma reavaliação das diretrizes curriculares previstas na Portaria $n^{\circ} 1.886 / 1994$ e retoma alguns argumentos defendidos na longínqua década de 50 .

Quanto aos paradigmas das Diretrizes Curriculares Nacionais, cumpre, de logo, destacar que elas objetivam "servir de referência para as instituiçóes na organização de seus programas de formação, permitindo flexibilidade e priorização de áreas de conhecimento na construção dos currículos plenos. Devem induzir à criaçáo de diferentes formações e habilitaçóes para cada área do conhecimento, possibilitando ainda definirem múltiplos perfis profissionais, garantindo uma maior diversidade de carreiras, promovendo a integraçáo do ensino de graduaçấo com a pós-graduação, privilegiando, no perfil de seus formandos, as competências intelectuais que reflitam a heterogeneidade das demandas sociais" (BRASIL, 2002).

Posteriormente, e após conclamar pelo engajamento das Instituiçôes de Ensino Superior no processo que encetaria mudanças profundas e contínuas no marco da formação jurídica, próprias para o envolvimento da comunidade institucional com as "exigências do meio", a partir da preocupação de formar profissionais verdadeiramente aptos para atuar na sociedade, o Conselho Nacional de Educação emite o Parecer CNE/CES 67/2003 que preconiza:

Com efeito, repita-se, não se cogita mais do profissional "preparado", mas do profissional apto às mudanças e, portanto, adaptável. Isto significa um marco histórico, porque, em matéria de concepção pedagógica do processo educativo e, consequentemente, das concepções das ações pelas quais a educação e o ensino venham a efetivar-se, sem dúvida haveria de ser repensada a elaboração dos currículos dos cursos de qualquer grau ou nível, especialmente os de graduação, convocadas que estavam todas as instituiçôes da comunidade para exercerem 
uma ação conjugada, harmônica e cooperativa, com o Poder Público e com outras instituiçóes, como se verifica no art. 205 da Constituição Federal ("com a colaboração da sociedade") e no art. 211 ("em regime de colaboração"), para resgatar a educação dos percalços em que se encontrava e ante os desafios acenados em novos horizontes da história brasileira e do mundo (BRASIL, 2003).

Diante deste contexto, surge a Resoluçáo no 9/2004, com o desígnio de reestruturar o ensino jurídico brasileiro a partir de uma pauta axioprincipiológica apta ao pleno envolvimento dos atores do sistema educacional no fluxo da formação jurídica.

\section{A FINALIDADE DA RESOLUÇÃO CNE/CES N 9/2004 E A RETOMADA DA BASE HUMANÍSTICA SUGERIDA POR SAN TIAGO DANTAS}

A Resolução CNE/CES n 9/2004, de 29 de setembro de 2004, surge na tentativa de repaginar as Diretrizes Curriculares do curso de Direito fixadas pela Portaria no $1.886 / 1994$, buscando, assim, atender às demandas identificadas tanto na ordem do sistema educacional brasileiro quanto no contexto social de atuação do egresso de um curso jurídico. Por esta linha, a nova proposta trazida pela Resolução 9/2004 preconiza que o processo de formação jurídica corresponde a um processo contínuo, autônomo e permanente, intrínseco à conformação de um perfil técnico-humano do profissional do Direito. Sob este aspecto, resulta o entendimento de que o egresso de um curso de Direito deve mostrar-se capaz de exercer o seu ofício e de participar das diferentes altercaçóes da vida social. Por esta linha, importante destacar que após uma intensa discussão celebrada entre o Conselho Nacional de Educação, a Associação Brasileira de Ensino de Direito (Abedi) e a Ordem dos Advogados do Brasil, colaborou para a adequação do texto final da Resolução no 9/2004 os termos do Parecer no CNE/CES 211/2004, que adverte:

[...] os obstáculos do ensino jurídico somente serão superados se as Diretrizes Curriculares Nacionais para a graduação em Direito, bacharelado, encontrarem do corpo docente e das administraçóes das instituições de ensino superior, o total compromisso de atender aos reclamos de uma nova época, constituindo-se efetivas respostas às novas aspiraçóes e às novas concepçóes jurídicas, ajustadas às 
necessidades locais, regionais, nacionais, internacionais, que estáo a exigir uma diversificação curricular, nas instituiçóes, na proporção direta das mudanças e das demandas regionais, atuais e emergentes (FRAUCHES, 2008, p. 199).

Dessa forma, visando a ajustar o ensino jurídico às disposiçóes da Lei de Diretrizes e Bases da Educação Nacional, as Instituiçóes de Ensino Superior deveriam incorporar em suas açôes a conjugação dos avanços científicos, tecnológicos e axiológicos necessários à compreensão dos fenômenos sociojurídicos de uma sociedade em constantes mudanças. Assim sendo, não poderiam furtar-se à promoção da especialização em diferentes áreas do Direito, com o fito de aproximar o profissional das demandas da comunidade em que vive.

Assim, o Direito retomará o seu papel de controle, construçáo e garantia do desenvolvimento da sociedade, evitando que se repita a postura cômoda de nada inovar, dando-se as faculdades por satisfeitas com a simples execuçáo do currículo mínimo em que já se transformara o "currículo pleno", como continua ocorrendo, bastando a realizaçáo e aprovaçáo da monografia. O ensino jurídico não pode comprazer-se com a emissão de diploma de graduação para aqueles que concluíram com aproveitamento médio, regular, as matérias ou disciplinas jurídicas estabelecidas na norma, muitas vezes cursadas mediana e compulsoriamente, apenas porque a norma (grade curricular) o exigiu, no limite do quantum satis para a sua creditação acadêmica (BRASIL, 2004).

A Resolução no 9/2004, entáo, é editada com o intuito de que os Projetos Pedagógicos dos cursos de Direito abandonem os currículos mínimos, já ultrapassados como mote de formaçáo do perfil do exercente da ciência do Direito exigido pelo mundo da vida, conforme sobrelevado pelo Parecer no CNE/CES 146/2002, no sentido de que:

$[\ldots]$

2) enquanto os Currículos Mínimos encerravam a concepção do exercício do profissional, cujo desempenho resultaria especialmente das disciplinas ou matérias profissionalizantes, enfeixadas em uma grade curricular, com os mínimos obrigatórios fixados em uma resolução por curso, as Diretrizes Curriculares Nacionais concebem a formação de nivel superior como um processo continuo, 
autônomo e permanente, com uma sólida formação básica e uma formação profissional fundamentada na competência teórico-prática, de acordo com o perfil de um formando adaptável às novas e emergentes demandas;

$[\ldots]$

4) enquanto os Currículos Mínimos muitas vezes atuaram como instrumento de transmissão de conhecimentos e de informaçóes, inclusive prevalecendo interesses corporativos responsáveis por obstáculos no ingresso no mercado de trabalho e por desnecessária ampliação ou prorrogação na duração do curso, as Diretrizes Curriculares Nacionais orientam-se na direção de uma sólida formação básica, preparando o futuro graduado para enfrentar os desafios das rápidas transformaçóes da sociedade, do mercado de trabalho e das condiçóes de exercício profissional;

5) enquanto o Currículo Mínimo profissional pretendia, como produto, um profissional "preparado", as Diretrizes Curriculares Nacionais pretendem preparar um profissional adaptável a situaçōes novas e emergentes (BRASIL, 2002).

Partindo desta concepção, a Resolução no 9/2004 sedimenta pontos cruciais que deveriam servir de guia para a comunidade acadêmica, vez que, por ora, se defendia uma maior liberdade e autonomia das instituiçóes de ensino na organização de seus cursos. Nesse sentido, a Resolução no 9/2004 veio deliberar sobre as especificidades aplicadas ao curso de Direito, a partir da concepção das diretrizes curriculares nacionais a serem observadas pelas instituiçóes educacionais ao elaborarem seu projeto pedagógico, como previsto em seu artigo $2^{\circ}$ :

[...] A organização do Curso de Graduação em Direito, observadas as Diretrizes Curriculares Nacionais, se expressa através do seu projeto pedagógico, abrangendo o perfil do formando, as competências e habilidades, os conteúdos curriculares, o estágio curricular supervisionado, as atividades complementares, o sistema de avaliação, o trabalho de curso como componente curricular obrigatório do curso, o regime acadêmico de oferta, a duração do curso, sem prejuízo de outros aspectos que tornem consistente o referido projeto pedagógico (FRAUCHES, 2008, p. 183, grifo nosso).

A Resolução CNE/CES 9/2004 oferece, então, os preceitos pedagógicos, técnicos e axiológicos intrínsecos à consolidação de um curso jurídico. Destaca-se, inicialmente, que o egresso de um curso de Direito deve, de todas as formas, apresentar "capacidade de análise, domínio de conceitos e da terminologia jurídica, ade- 
quada argumentação, interpretação e valorização dos fenômenos jurídicos e sociais" (FRAUCHES, 2008, p. 184), com vistas a desenvolver "uma postura reflexiva e de visão crítica que fomente a capacidade e a aptidão para a aprendizagem autônoma e dinâmica, indispensável ao exercício da Ciência do Direito, da prestação da justiça e do desenvolvimento da cidadania" (FRAUCHES, 2008, p. 184).

Vistas estas previsões, percebe-se claramente um resgate da visão humanista no processo formacional do acadêmico de Direito, o que o tornará um profissional mais preocupado com seu entorno e capaz de acompanhar, de forma mais efetiva, as transformações da sociedade.

De outra forma, a Resolução no 9/2004 pauta, também, pelo necessário estímulo ao desenvolvimento de competências e habilidades, além da fixação de uma organização curricular que sustente a construção do próprio perfil do graduando durante a realização do curso.

Desta maneira, a Resolução de 2004 elenca em seu texto um rol exemplificativo das habilidades e competências que devem ser desenvolvidas pelo egresso, independentemente de outras congêneres com a contextualização do curso, do entorno e do perfil da própria IES. Ditas habilidades e competências, por certo, não se totalizam em si mesmas, e representam os predicados mínimos que um curso de Direito deve oferecer ao seu egresso, conforme se observa a seguir:

Art. $4^{\circ}$. O curso de graduação em Direito deverá possibilitar a formação profissional que revele, pelo menos, as seguintes habilidades e competências:

I - leitura, compreensão e elaboração de textos, atos e documentos jurídicos ou normativos, com a devida utilização das normas técnico-jurídicas;

II - interpretação e aplicação do Direito;

III - pesquisa e utilização da legislação, da jurisprudência, da doutrina e de outras fontes do Direito;

IV - adequada atuação técnico-jurídica, em diferentes instâncias, administrativas ou judiciais, com a devida utilização de processos, atos e procedimentos; V - correta utilização da terminologia jurídica ou da Ciência do Direito;

VI - utilização de raciocínio jurídico, de argumentaçáo, de persuasáo e de reflexão crítica;

VII - julgamento e tomada de decisóes; e,

VIII - domínio de tecnologias e métodos para permanente compreensão e aplicaçáo do Direito (FRAUCHES, 2008, p. 184). 
Além das competências e habilidades previstas para o graduando, a Resolução 9/2004 estabelece que as Instituiçóes de Ensino Superior devem organizar, em seu projeto, os componentes curriculares do seu curso de Direito, compostos de conteúdos e atividades distribuídos em três eixos formacionais, interligados entre si: um eixo de formação fundamental, destinado a propiciar ao acadêmico uma base humanística, inter-relacionando o Direito com outras áreas de conhecimento; um eixo de formação profissional, fortalecido no estudo sistemático e contextualizado de diversos ramos do Direito, desde o prisma dogmático e epistemológico, valorizando a análise sociopolítica e econômica dos fenômenos sociojurídicos, sobretudo atinente à aplicação do Direito às transformaçóes vivenciadas na sociedade brasileira; e, por fim, um eixo de formação prática, que visa a integrar os conteúdos teóricos desenvolvidos nos eixos de formação fundamental e profissional às açóes práticas pertinentes ao curso.

Para tanto, o artigo 5o da Resolução no 9/2004 estabelece os conteúdos essenciais que devem abranger os eixos de formação fundamental e profissional, assim como designa as atividades, mínimas e obrigatórias, de cunho prático, que devem ser desenvolvidas durante a realização do curso.

Art. $5^{\circ}$

$[\ldots]$

I - Eixo de Formação Fundamental, [...] abrangendo, dentre outros, estudos que envolvam conteúdos essenciais sobre Antropologia, Ciência Política, Economia, Ética, Filosofia, História, Psicologia e Sociologia.

II - Eixo de Formação Profissional, [...] incluindo-se necessariamente, dentre outros condizentes com o projeto pedagógico, conteúdos essenciais sobre Direito Constitucional, Direito Administrativo, Direito Tributário, Direito Penal, Direito Civil, Direito Empresarial, Direito do Trabalho, Direito Internacional e Direito Processual; e

III - Eixo de Formação Prática, [...] atividades relacionadas com o Estágio Curricular Supervisionado, Trabalho de Curso e Atividades Complementares (FRAUCHES, 2008, p. 184). 
A partir desta concepção cria-se a expectativa de que a organização curricular de um curso de Direito ultrapassa o modelo rígido de disposiçāo de um mínimo de matérias, e passa à estruturação de uma disposição de conteúdos inter-relacionados com a realidade nacional e internacional, que observem um enfoque histórico, a ser contextualizado diante dos mais diversos fenômenos sociojurídicos, de modo a conjugar os três eixos de formação.

\section{CONSIDERAÇÕES FINAIS}

Destarte o cenário de sempiterna crise do ensino jurídico no Brasil, entende-se que a Resolução CNE/CES no 9/2004, diferente da Portaria n ${ }^{\circ} 1.886 / 2004$, atendeu ao pressuposto da formação jurídica humanística, estabelecendo, no arquétipo das Diretrizes Curriculares Nacionais para o curso de Direito, um marco axioprincipiológico, que fraciona o juízo tecnicista do ensino jurídico. Estabeleceu, ainda, um perfil para o acadêmico de Direito, o qual deveria ser estimulado e desenvolvido durante os cinco anos em que o estudante estivesse realizando seu curso.

É nítido, assim, que a vigente Resoluçáo CNE/CES no 9/2004 eleva a importância de uma sólida formação humanística e axiológica do graduando, demarcando que este deverá ser dotado de uma postura crítico-reflexiva, primordial na formação do profissional engajado em seu entorno social, imbuído, sobretudo, do espírito de justiça e cidadania. Nesse sentido, viabilizou que as Instituiçôes de Ensino Superior ajustem a organizaçáo curricular de seus cursos de Direto em consonância com as demandas da comunidade na qual estáo inseridas, aproximando o mundo acadêmico da realidade social.

Ante o avanço principiológico aportado pela Resolução CNE/CES no 9/2004, percebe-se uma inclinaçáo ao entendimento de San Tiago Dantas, pelo menos em seu aspecto formal. Resta, porém, compreender as razóes que suscitam, até os dias de hoje, tantas discussóes acerca do ensino jurídico no Brasil, evidenciando uma perpétua crise que promove a desarmonia entre as entidades envolvidas com o marco formativo. 
Talvez, para compreender-se esta questáo, deva-se reportar outro questionamento suscitado por San Tiago Dantas: "Como vivificar a educação jurídica?” Dantas acreditava que, para fortalecer o ensino jurídico, primeiramente seria necessária a retificaçáo do estudo expositivo, abrindo-se espaço para o raciocínio jurídico lastreado na soluçáo de controvérsias com uma participaçáo mais intensa do aluno no processo de ensino e aprendizagem; para, posteriormente, por meio da flexibilidade curricular, possibilitar que o estudante pudesse, deliberadamente, especializar-se em áreas que atendessem às perspectivas da comunidade na qual se estabeleceria pessoal e profissionalmente (DANTAS, 2009).

Sem embargo, ainda que este pensamento estivesse impregnado na gênese das novas diretrizes curriculares, em linha diametralmente oposta, a postura dos atores do processo educacional rumam para o lado oposto.

Vivencia-se, uma e outra vez, o ensino jurídico com o perfil da formação "caçamba ou tombadeira", por meio do qual o estudante é alimentado pelo corpo docente, tão somente com informaçóes provenientes dos programas da disciplina, cujo conteúdo espera-se que seja despejado em uma folha de papel ao realizar-se uma avaliação. Desta forma, de um lado, atende-se aos requisitos institucionais da prescrição integral de conteúdos e demais formalidades presentes nos planos de ensino, ao passo que, de outro, suplanta-se o desenvolvimento de uma postura crítica diante da reflexão acerca dos fenômenos sociojurídicos (MIRANDA, 2009).

Torna-se evidente, então, que a simples existência de uma pauta normativa que revista de aspecto humanístico o modelo de educação jurídica não garante a adoção de medidas que tornem efetivo o processo de ensino e aprendizagem. Insta, pois, uma ação efetiva por parte do corpo acadêmico, e aqui deve ser ressaltada a figura do docente e do gestor institucional, no sentido de invocar açóes eficazes, preocupadas com novas metodologias de ensino, capazes de formar profissionais com competências e habilidades que não se restrinjam a um conhecimento técnico que, muitas vezes, ficou esquecido após a realização de uma prova.

Percebe-se, de outra banda, que não foi necessário aguardar uma década para se compreender os deslizes do sistema educacional. O próprio Ministério da Educação, no Parecer CNE/CES no 211/2004, fornecido poucos meses antes da edição da Resolução no 9/2004, já alertava para a existência de matérias e discipli- 
nas de aplicação tecnicista e dogmática, sem um compromisso com a nova ordem política, econômica e social, recomendando que o caminho a ser seguido deveria contemplar a autonomia intelectual e o raciocínio jurídico, com um forte viés de “[...] cientificidade e criticidade, epistemologicamente sedimentados, centrados também em uma escala de valor dignificante para o Brasil, para a pessoa humana e para os cidadãos [...]" (FRAUCHES, 2008, p. 200).

Diante de todo o exposto, depreende-se que as mazelas da educação jurídica no Brasil prescindem de uma revisão dos instrumentos normativos que regem as diretrizes curriculares do curso de Direito. Em verdade, carecem de uma reavaliação da postura atitudinal da comunidade acadêmica, que somente poderá ser efetivada em um espaço de gestão democrática, em que todos os envolvidos no processo de ensino e aprendizagem não apenas tenham voz, mas possam refletir profundamente sobre as demandas que emergem do seu meio e que revelem profundas preocupaçóes com o desenvolvimento pessoal, intelectual e profissional do acadêmico do Direito, enquanto ser gregário que pertence a uma sociedade em constante transformação.

\section{REFERÊNCIAS}

BASTOS, A. W. Ensino jurídico no Brasil. 2. ed. Rio de Janeiro: Ed. Lúmen Júris, 2000.

BRASIL. Constituição da República Federativa do Brasil. Brasília, DF: Senado Federal, 1988. . Lei n ${ }^{\circ}$ 9.394, de 20 de dezembro de 1996. Estabelece as diretrizes e bases da educação nacional. Diário Oficial [da] República Federativa do Brasil, Brasília, DF, p. 27.833, 23 dez. 1996. Seção 1.

. Lei $\mathrm{n}^{\circ} 10.172$, de 9 de janeiro de 2001. Aprova o Plano Nacional de Educação e dá outras providências. Diário Oficial [da] República Federativa do Brasil, Brasília, DF, p. 1, 10 jan. 2001. Seção 1.

- Ministério da Educação. Parecer Conselho Nacional de Educação/ Câmara de Educação Superior no 211/2004. Reconsideração do Parecer CNE/CES 55/2004, referente às Diretrizes Curriculares Nacionais para o curso de graduação em Direito. 2004. Disponível em: <http://portal.mec.gov.br/cne/arquivos/pdf/2004/pces211_04.pdf>. Acesso em: 21 jun. 2017. 
BRASIL. Ministério da Educação. CNE revisa diretrizes do curso e recebe sugestóes da $O A B$. Disponível em: <http://portal.mec.gov.br/component/content/article?id=45381>. Acesso em: 10 jun. 2017.

. Ministério da Educação. Parecer Conselho Nacional de Educação no 776/1997. Orienta para as diretrizes curriculares dos cursos de graduação. 1997. Disponível em: <http://portal. mec.gov.br/setec/arquivos/pdf_legislacao/superior/legisla_superior_parecer77697.pdf>. Acesso em: 21 jun. 2017.

. Ministério da Educação. Parecer Conselho Nacional de Educação/Câmara de Educação Superior no 146/2002. Diretrizes Curriculares Nacionais dos cursos de Graduaçáo em Direito, Ciências Econômicas, Administração, Ciências Contábeis, Turismo, Hotelaria, Secretariado Executivo, Música, Dança, Teatro e Design. 2002. Disponível em: <http://portal.mec.gov. br/cne/arquivos/pdf/CES0146.pdf>. Acesso em: 21 jun. 2017.

- Ministério da Educação. Parecer Conselho Nacional de Educação/ Câmara de Educação Superior $n^{\circ}$ 67/2003. Referencial para as Diretrizes Curriculares Nacionais - DCN dos Cursos de Graduação. 2003. Disponível em: <http://portal.mec.gov.br/cne/arquivos/pdf/ CES0067.pdf>. Acesso em: 21 jun. 2017.

DANTAS, F. C. S. T. A educação jurídica e a crise brasileira. Cadernos FGV Direito Rio Educação e Direito, Rio de Janeiro, v. 3, p. 9-38, fev. 2009. Disponível em: <http://bibliotecadigital.fgv.br/dspace/bitstream/handle/10438/10400/Cadernos\%20FGV\%20Direito\%20 Rio\%20-\%20Vol.\%203.pdf?sequence=1>. Acesso em: 17 mar. 2017.

DANTAS, S. T. Palavras de um professor. 2. ed. Rio de Janeiro: Forense, 2001.

DURAN, A. A. C. A ideia de humanismo no ensino jurídico brasileiro. Justiça e História, v. 6, n. 11, p. 84-135, nov. 2006. Disponível em: <http://file://C:/Users/pesquisa12/ Downloads/ID\%C3\%89IA\%20DE\%20HUMANISMO\%20NO\%20ENSINO\%20 JUR\%C3\%8DDICO_tjrs.pdf>. Acesso em: 17 mar. 2017.

FRAUCHES, C. C.; FAGUNDES, G. M. LDB anotada e comentada e reflexóes sobre a educação superior. 2. ed. Brasília: Ilape, 2007.

FRAUCHES, C. C. (Org.). Diretrizes curriculares para os cursos de Graduação. Brasília: Abmes Editora, 2008.

FREIRE, P. Pedagogia da autonomia: saberes necessários à prática educativa: São Paulo: Paz e Terra, 1996.

MACHADO, A. A. Ensino jurídico e mudança social. 2. ed. São Paulo: Expressão Popular, 2009. 
MIRANDA, J. E. Da didática do ensino jurídico aos novos paradigmas para a sustentabilidade da formação em direito: uma resenha metamorfótica. Revista da Ena, Brasília, DF, p. 27-40, dez. 2009. Disponível em: <http://arquivos.integrawebsites.com.br/6496/dabcab3d6515afda7ae650bc320eb9f1.pdf>. Acesso em: 17 mar. 2017.

. Maldita facul... tô dentro e agora? Curitiba: Editora Prismas, 2017.

OLIVEIRA, José Sebastião de. O perfil do profissional do Direito neste início de século XXI. Revista Jurídica Cesumar, Maringá: Unicesumar, v. 3, n. 1, p. 61-88, 2003.

ORDEM DOS ADVOGADOS DO BRASIL (OAB). OAB Ensino Jurídico: o futuro da universidade e os cursos de direito: novos caminhos para a formação profissional. Brasília: OAB; Conselho Federal, 2006.

. Comissáo nacional apresentará proposta para nova diretriz curricular do curso de direito. Disponível em: <http://www.oabes.org.br/noticias/comissao-nacional-apresentara-proposta-para-nova-diretriz-curricular-do-curso-de-direito-558252.html>. Acesso em: 10 jun. 2017.

PORTO, I. F. Ensino jurídico, diálogos com a imaginação: construção do projeto didático no ensino jurídico. Porto Alegre: Sérgio Antônio Fabris Editor, 2000.

RODRIGUES, H. W. Pensando o ensino jurídico no século XXI: diretrizes curriculares, projeto pedagógico e outras questóes pertinentes. Florianópolis: Fundação Boiteux, 2005.

SANTOS, B. S. Da ideia de universidade à universidade de ideias. Revista Critica de Ciências Sociais, n. 27/28, jun. 1989. Disponível em: <http://Da_ideia_de_universidade_RCCS2728.PDF>. Acesso em: 27 abr. 2017.

UNIVERSIDADE FEDERAL DO PAMPA. Audiência pública debate novas diretrizes curriculares para o curso de direito. Disponível em: <http://novoportal.unipampa.edu.br/ novoportal/audiencia-publica-debate-novas-diretrizes-curriculares-para-o-curso-de-direito $>$. Acesso em: 21 jun. 2017. 